\title{
Radial Growth of Multi-Walled Carbon Nanotubes in Aligned Sheets through Cyclic Carbon Deposition and Graphitization
}

\author{
Shaghayegh Faraji a, Ozkan Yildiz ${ }^{a}$, Christina Rost ${ }^{\text {b }}$, Kelly Stano ${ }^{\text {a }}$, Nasim \\ Farahbakhsh $^{\text {a }}$, Yuntian Zhu ${ }^{\text {b }}$ and Philip D. Bradford ${ }^{\text {a, } * 1}$ \\ ${ }^{a}$ Department of Textile Engineering, Chemistry and Science, North Carolina State \\ University, Campus Box 8301, Raleigh, NC 27695, USA \\ ${ }^{\mathrm{b}}$ Department of Materials Science and Engineering, North Carolina State University, \\ Campus Box 7907, Raleigh, NC 27695, USA
}

\begin{abstract}
Carbon coated aligned multi-walled carbon nanotube (AMWCNT/C) sheets were used for studying the controlled radial growth of MWCNTs. Pyrolytic carbon (PyC) was deposited on the surface of nanotubes using multiple cycles of chemical vapor infiltration. Morphological and structural characterization showed that when graphitization was done in one step, after the deposition of multiple cycles of PyC, the presence of a large amount of disordered carbon on the surface of nanotubes led to a poorly graphitized coating structure that did not resembled nanotube walls anymore. Graphitization of the AMWCNT/C sheets after each deposition cycle prevented the development of disordered carbon during the subsequent PyC deposition cycles. Using the cyclic-graphitization method, thick PyC coating layers were successfully graphitized into a crystalline structure that could not be differentiated from the original nanotube walls. TEM observation and X-ray data confirmed radial growth of nanotubes, while spectra collected from Raman spectroscopy revealed that radially grown CNTs had the
\end{abstract}

\footnotetext{
${ }^{* 1}$ Corresponding author. Tel: 919-515-1866. E-mail: philip_bradford@ncsu.edu (Philip Bradford)
} 
same quality as graphitized pristine nanotubes. The focus of this study was to compare the effect of cyclic graphitization with a one-step graphitization method to gain insight on the necessary parameters needed to radially grow high quality CNTs.

\section{Introduction}

Carbon/carbon $(\mathrm{C} / \mathrm{C})$ composites have a combination of outstanding mechanical, thermal and electrical properties and therefore have been widely investigated as a class of advanced, high-performance materials. The largest application of $\mathrm{C} / \mathrm{C}$ composites is in brake discs for military, civilian and commercial aircraft. However, these composites also find applications in rocket nozzles, nose cones, re-entry vehicle and thermal protection systems in space shuttles.

While carbon fibers $(\mathrm{CF})$ have been used traditionally as the reinforcement phase for these composites, there has been a growing interest in application of carbon nanotubes (CNT) in C/C composites. Previous studies mainly focused on the effect of CNTs as the secondary reinforcement material in $\mathrm{C} / \mathrm{C}$ composites [1-8]. More recent studies have considered the application of nanotubes as the main filler materials in $\mathrm{C} / \mathrm{C}$ composites [912]. Inspired by the common production routes for $\mathrm{C} / \mathrm{C}$ composites, chemical vapor infiltration (CVI) of pyrolytic carbon (PyC) and polymer impregnation and pyrolysis (PIP) methods are used to create the carbon matrix in CNT/carbon (CNT/C) composites.

Graphitization is known as the process where heat treatment at elevated temperatures is used to gradually change the structure of disordered carbon materials toward ordered graphite [13]. Studies exploring the effect of CNTs on the graphitization of carbon matrices have shown that nanotubes can induce stress graphitization in nongraphitizing carbon matrices which are derived from liquid resins [14,15]. Increasing 
content and degree of CNT alignment improved formation of graphitic regions in these matrices $[15,16]$. Despite the wide application of graphitization processes in industry and the effect of these processes on microstructure and properties of carbon composites, works exploring the graphitization of CNT/C composites have been mostly limited to the composites fabricated through the polymer infiltration and pyrolysis method. For CNT/C composites fabricated through CVI technique, the majority of the studies are only focused on mechanism and morphology of PyC deposition on the CNT preforms [11,17-20]. In our previous work [21], we studied the graphitization behavior of PyC coated aligned multiwalled CNT (AMWCNT/C) composite sheets. Graphitization of the composites at 2150 ${ }^{\circ} \mathrm{C}$ for 5 hours provided different results for different thickness of PyC coatings. Thinner PyC coatings, from short deposition durations, were graphitized to a large extent and resulted in a crystalline structure that resembled nanotube walls. Further thickening of the PyC layer, however, did not yield a highly ordered structure after graphitization. This was attributed to the development of a much more disordered layer at the surface of the coating as the coating thickness increased by prolonging the infiltration duration. Previous studies have also reported this structural transition toward a disordered carbon at the surface of the coating[11,20]. It was therefore concluded that there is a limit to the thickness of PyC coating layer that can graphitize into additional walls on the surface of CNTs.

This work presents a new approach to control the structure of PyC coatings on CNTs to avoid the development of disorder carbon as the coating layer becomes thicker. Through a "cyclic graphitization" method, PyC coatings with thicknesses much beyond the previously observed limit were graphitized to a large extent into a crystalline structure similar to nanotube walls. To show the importance of doing the graphitization treatment 
in cycles, samples were also prepared by doing the graphitization treatment in one-step. The structure and morphology of the resulting PyC coatings were compared.

\section{Experimental}

\subsection{Synthesis of MWCNTs}

Vertically aligned multi-walled CNT (MWCNT) arrays were fabricated using modified chlorine mediated chemical vapor deposition (CVD) method. Detailed explanation of the growth procedure is available elsewhere [22]. In short, arrays were grown on quartz substrates in a horizontal tube furnace at $760{ }^{\circ} \mathrm{C}$, using acetylene as the precursor and $\mathrm{FeCl}_{2}$ (anhydrous 99.5\% VWR) as the catalyst. During the growth, pressure of the system was kept at 3 Torr while a mixture of process gases (acetylene, argon and chlorine) flowed at $1000 \mathrm{sccm}$. After 15 minutes of growth, the resulting arrays were $\sim 2 \mathrm{~mm}$ tall with an average diameter $\sim 40 \mathrm{~nm}$ as measured from TEM images. Pristine arrays could be easily drawn into horizontally aligned CNT sheets for further processing.

In order to ensure that any secondary reactions from iron catalyst impurities would not occur and influence the structure of the coatings, iron impurities were removed through a high temperature chlorine treatment. Pristine arrays were re-loaded inside the furnace and underwent chlorine treatment for 15 minutes at $760{ }^{\circ} \mathrm{C}$ and 3 Torr. During the treatment, iron impurities quickly react with chlorine at high temperatures and produce $\mathrm{FeCl}_{2}$ vapor that leaves the furnace tube [23]. Our previous studies showed that iron content of the arrays decreased by $65 \%$ after high temperature chlorine treatment [21]. Any remaining iron is thought to be trapped inside of the CNTs (see for example Figure 1d in reference 22) and would not affect the structure of carbon coatings . 


\subsection{AMWCNT/C Composite Fabrication}

Single layer sheets of AMWCNT were drawn from CNT arrays and were used as the preform for PyC deposition. These sheets were $\sim 20 \mu \mathrm{m}$ thick and had a very low density of $0.002 \mathrm{~g} / \mathrm{cm}^{3}$. Using a highly porous preform with super low-density would ensure coating uniformity and reduce any variation in carbon deposition due to diffusion length limitation. This was important for collecting accurate CNT diameter distribution measurements and TEM micrographs of the coatings. These single layer sheets were wrapped around graphitic frames and were further loaded inside the CVI furnace for deposition of PyC. As mentioned earlier, samples were prepared using two different methods. Each preparation method is explained in detail in the following paragraph.

For preparation of cyclic graphitized samples, PyC was first deposited for 20 minutes on the surface of AMWCNT sheets. Deposition was accomplished using acetylene as the carbon source (600 sccm flow rate) at a deposition temperature of $800{ }^{\circ} \mathrm{C}$ while the pressure was maintained at 30 Torr. The samples were then graphitized in a high temperature furnace (RED DEVIL vacuum furnace WEBB 124) for 5 hours at 2150 ${ }^{\circ} \mathrm{C}$ in $\operatorname{argon}\left(99.999 \%\right.$ purity) atmosphere. An in-line oxygen/ $\mathrm{H}_{2} \mathrm{O}$ trap (Concoa 580-1600 series) was used to further reduce the oxygen concentration of gas stream to less than 15 ppb. After graphitization, those samples were considered to have one cycle of PyC deposition and graphitization. This process $(20$ minutes of PyC deposition and subsequent graphitization for 5 hours) was repeated for two, three and four cycles to prepare samples with two, three and four cycles of PyC deposition and graphitization. These samples were labeled and referred to as $2 \mathrm{C} / \mathrm{G}, 3 \mathrm{C} / \mathrm{G}$ and $4 \mathrm{C} / \mathrm{G}$ respectively. 
For preparation of one-step graphitized samples, deposition of PyC was similarly done in cycles of 20 minutes using the same deposition parameters. This was done to ensure that the condition of $\mathrm{PyC}$ deposition was exactly the same for samples prepared using either of the methods. In fact, PyC deposition on cyclic graphitized and one-step graphitized samples happened at the same time for each deposition cycle. However, onestep graphitized samples were not graphitized in between deposition cycles. Instead, they underwent graphitization process after they were infiltrated with $\mathrm{PyC}$ for the desired number of cycles (two, three or four). After carbon deposition, samples with two, three and four cycles of PyC deposition were graphitized for 10, 15 and 20 hours, respectively. These samples were labeled and referred to as $2 \mathrm{C} / \mathrm{FG}, 3 \mathrm{C} / \mathrm{FG}$ and $4 \mathrm{C} / \mathrm{FG}$. The durations of the graphitization process were chosen so that samples with the same number of $\mathrm{PyC}$ deposition cycles, but prepared using different methods (cyclic graphitization versus onestep graphitization), were kept at the graphitization temperature for the same amount of time. The conditions for one-step graphitization were the same as the cyclic graphitization method. Schematics in Figure 1 show the differences between the graphitization methods. 


\section{A) "Cyclic Graphitization” Method}

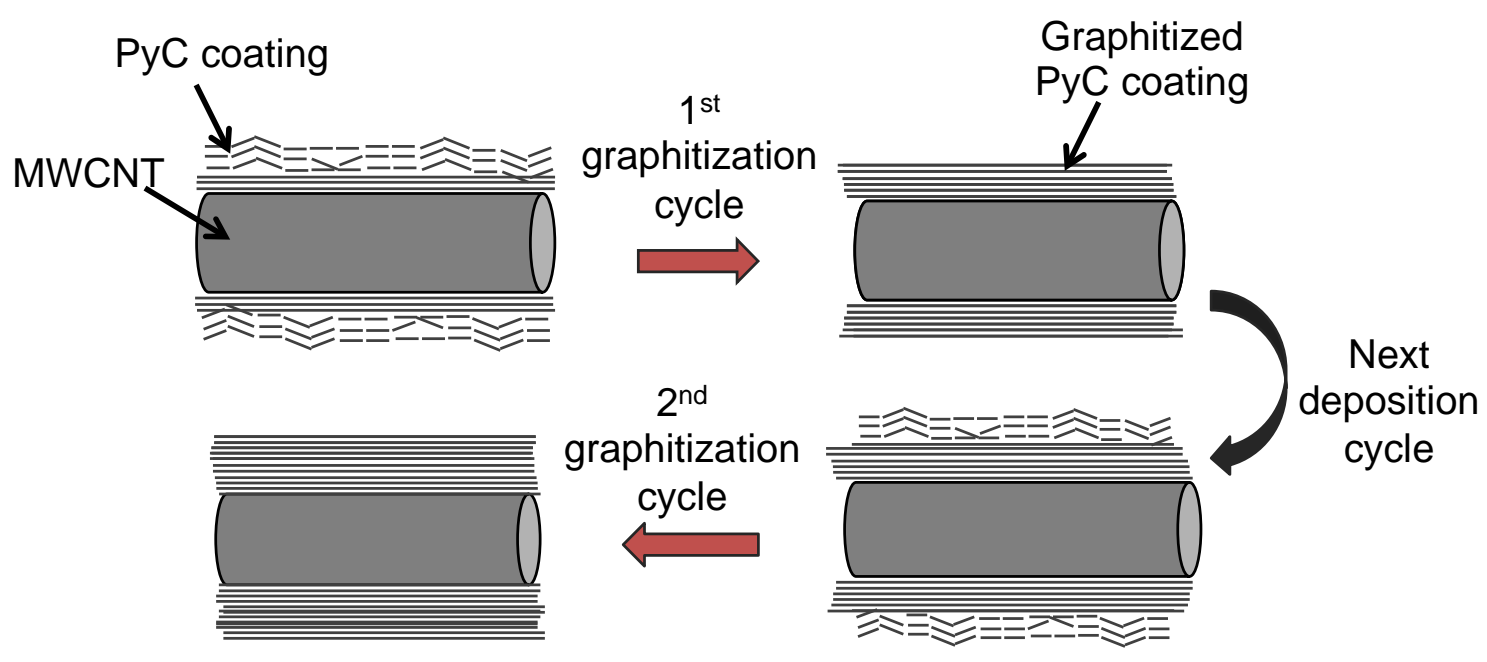

\section{B) “One-step Graphitization" Method}
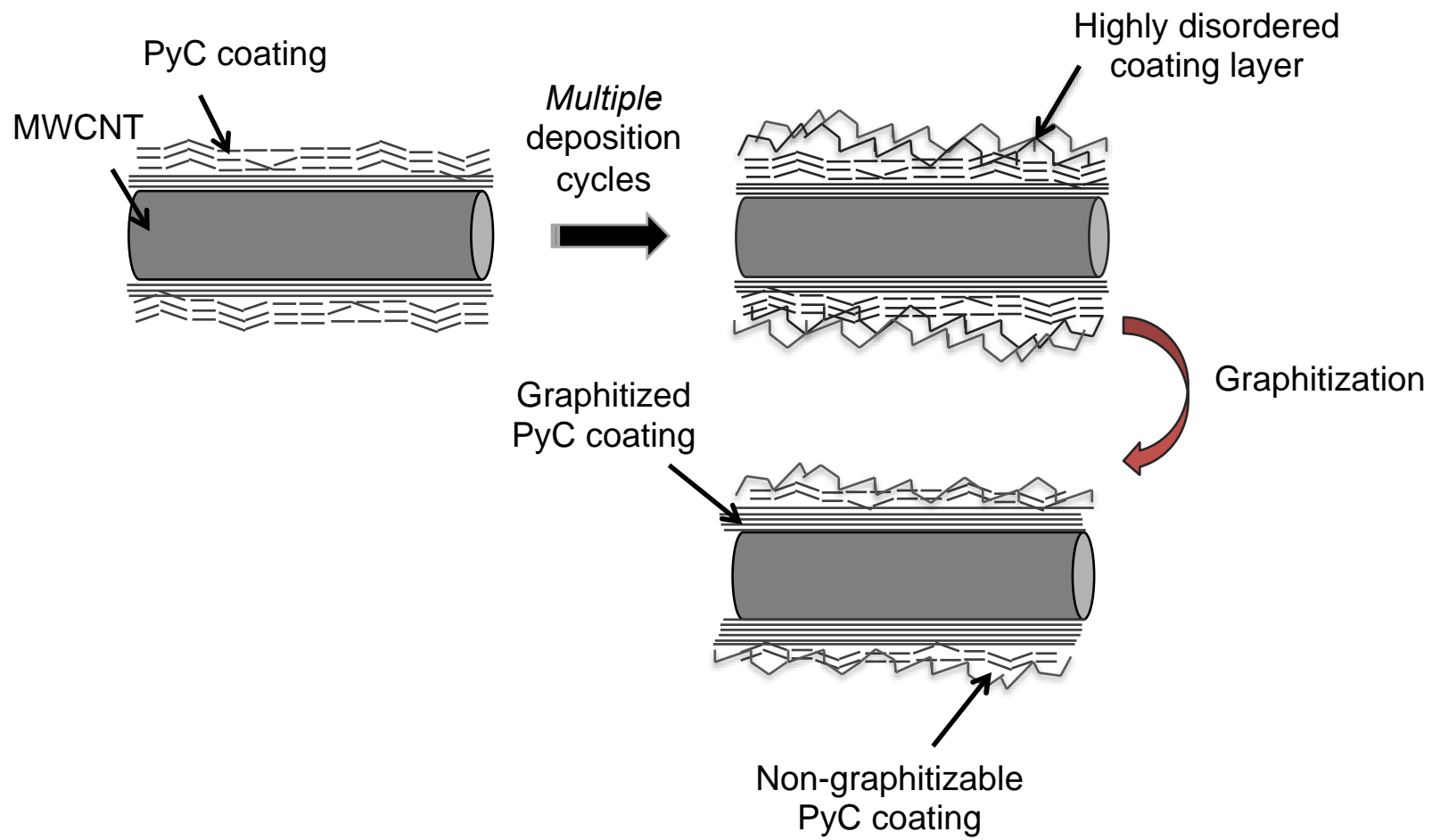

Figure 1 Schematics showing A) cyclic graphitization and B) one-step graphitization methods. 
Single layer AMWCNT/C composite sheets were used for Transmission electron microscopy (TEM) and Raman analysis. For X-ray diffraction (XRD) and Thermogravimetric analysis (TGA) experiments however, thicker samples were needed to increase the accuracy of the measurements. To make thick sheets of AMWCNT, horizontally aligned sheets of nanotubes were drawn from CNT array and continuously collected around two rotating parallel glass rods. The winding process continued for 10 minutes while the rods were rotating at $13 \mathrm{rpm}$. The resulting layered CNT sheets were $5 \mathrm{~mm}$ thick and were separated from the glass rods using a razor blade. These thick AMWCNT sheets were used as the preform for $\mathrm{PyC}$ deposition and were further processed the same as single layer AMWCNT/C composites. Figure 2 shows the steps taken to make AMWCNT/C sheets. 

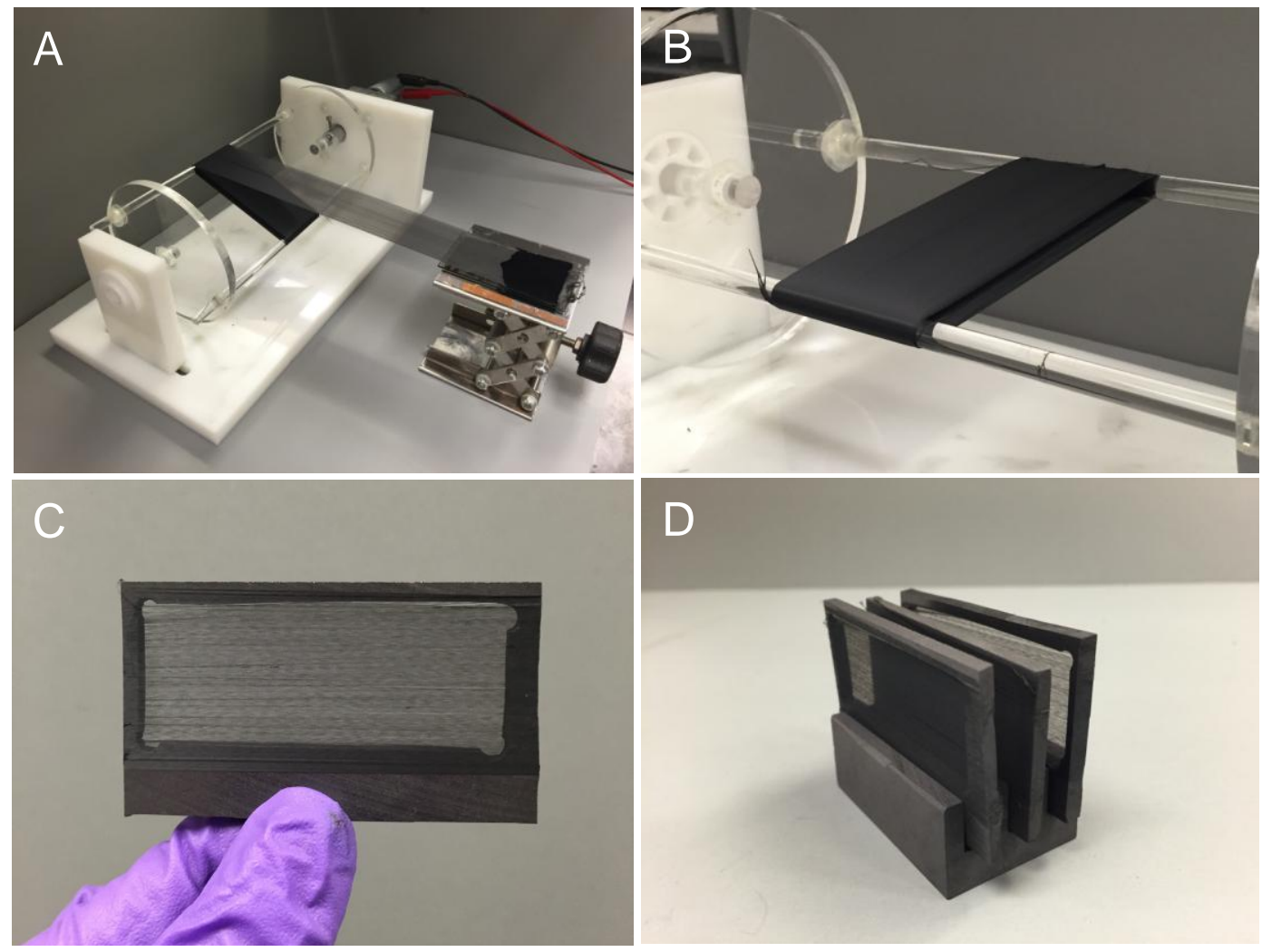

Figure 2 A) Winding of thicker, multi-layer AMWCNT sheets. B) $5 \mathrm{~mm}$ thick, multilayer AMWCNT sheets before separation from the glass rods. C) Single sheet of AMWCNT wrapped around graphitic frame. D) Single sheets of AMWCNT/C after PyC deposition.

\subsection{Characterization}

Transmission electron microscopy was conducted on a JEOL 2010FX TEM operating at $200 \mathrm{kV}$. Sonication was used to disperse a small amount of AMWCNT/C composites in ethanol. A droplet of the dispersion was then deposited on a TEM carbon grid and was left to dry. Diameter of pristine and PyC coated CNTs were measured from TEM images using ImageJ software. Average diameters were calculated from 100 measurements for each sample. 
A Renishaw 2000 Raman spectroscope (514 nm laser wavelength, 50x magnification) was used to probe the graphitic quality of the samples. Single layer sheets of AMWCNT/C composites were mounted on microscope slides and spectra was obtained from five different locations of each sample.

The X-ray diffraction (XRD) experiment was done using a PANalytical Empyrean diffractometer with 7-circle goniometer configuration ( $\mathrm{CuK} \alpha$ source, $\lambda=1.5406 \AA$ wavelength). Each sample was continuously scanned for $2 \theta=20-60^{\circ}$, while nanotubes were aligned parallel to the sample stage. As mentioned before, thick sheets of AMWCNT/C composites were used for XRD and TGA experiments to ensure the accuracy of measurements. However, despite using thick samples, signal intensity of XRD scans were lower than expected. This was probably due to the very low density of thick sheets and interaction depth limitation. To increase the signal intensity and make XRD measurements possible, thick sheets of AMWCNT/C were densified by infiltrating a dilute epoxy solution and further curing under pressure. A piece of quartz filter paper was placed under each sample to absorb excess solution. The background of the amorphous epoxy along with quartz filter was measured and subtracted from the spectra of each sample.

Thermal stability of the samples was tested using a Perkin Elmer Pyris Thermogravimetric analyzer (TGA). During TGA experiments, 5-10 mg of each sample was heated in air to $900{ }^{\circ} \mathrm{C}$ at a $20{ }^{\circ} \mathrm{C} / \mathrm{min}$. heating rate. 


\section{Results and Discussions}

Figure 3 shows changes in density with increasing number of PyC deposition cycles. For both the cyclic graphitization and one-step graphitization methods, the density of the AMWCNT/C composites increased linearly and with the same rates as the number of deposition cycles increased. There is a small variation $\left( \pm 0.3 \mathrm{mg} / \mathrm{cm}^{3}\right)$ in the density of pristine AMWCNT sheets ( 0 deposition cycle) that naturally happens during the winding process. Due to this variation in density of CNT preforms, the density of AMWCNT/C composites prepared by one-step graphitization method was slightly higher than those prepared by cyclic graphitization method and is the cause of the slight offset of the two best fit lines shown in Figure 3.

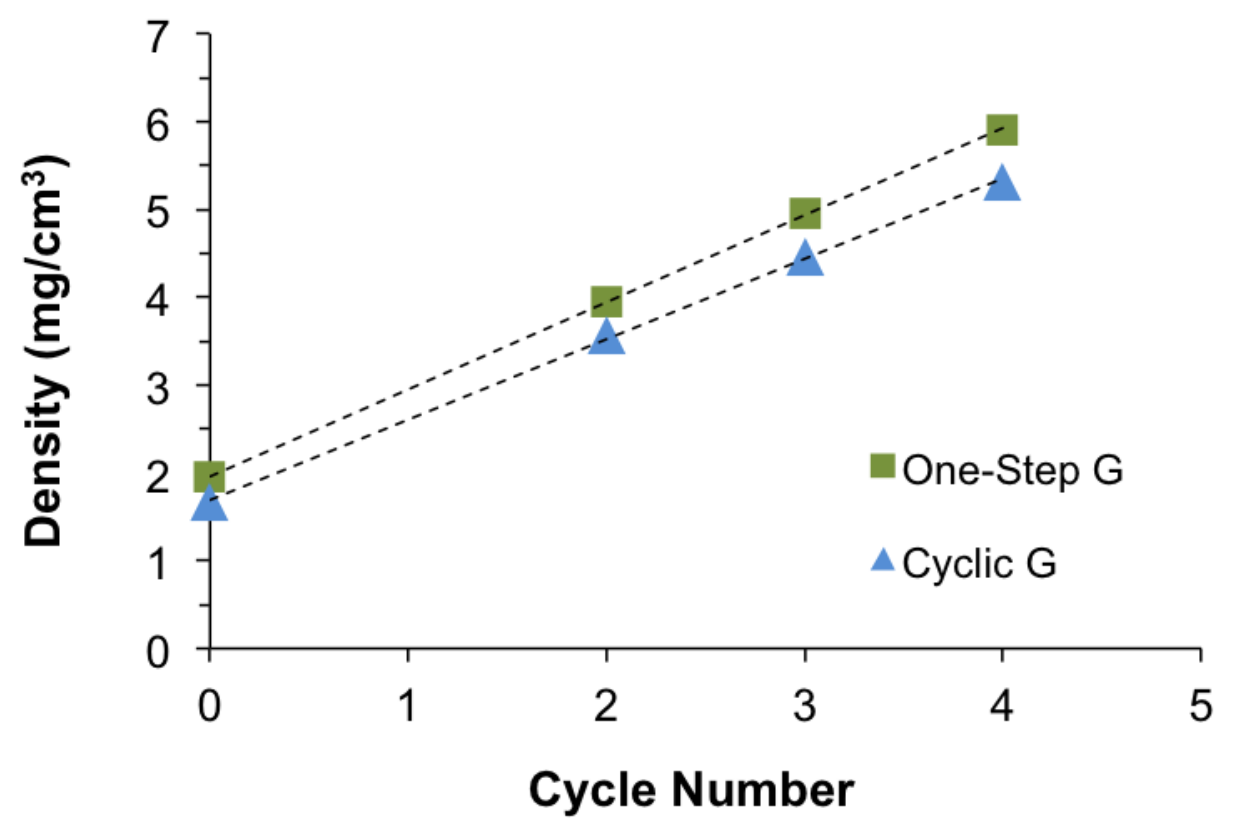

Figure 3 Changes in density of AMWCNT/C composites prepared with different methods. 


\subsection{Morphology of AMWCNT/C Composites}

TEM images in Figure 4 show the structure of samples with two, three and four cycles of PyC deposition, prepared with either one-step graphitization or cyclic graphitization methods. As shown in these images, there is a distinct difference in the structure of samples prepared using each methods. For cyclic graphitized samples (2 C/G, $3 \mathrm{C} / \mathrm{G}$ and $4 \mathrm{C} / \mathrm{G}$ ), PyC coating layers rearranged during graphitization cycles, resulting in a crystalline structure where the coating and original tube walls could not be easily differentiated. In contrast, images of one-step graphitized samples ( 2 C/FG, 3 C/FG and 4 $\mathrm{C} / \mathrm{FG})$ showed that the deposited carbon layers could not graphitize and remained disordered even after prolonged (10,15 and 20 hours) graphitization runs.

In the one-step graphitization method, graphitization was done after a thick layer of coating was achieved through multiple cycles of PyC deposition. Our previous study showed that for the deposition conditions of our CVI system, structural transition toward a disordered carbon happens after 30 minutes of PyC deposition[21]. Since each deposition cycle in this work was for 20 minutes, a very disordered carbon structure was developed after multiple cycles of PyC deposition. Previous studies[24-26] have shown that changes in the surface characteristics of the substrate, such as roughness and concentration of active sites, can affect the structure of deposited carbon. In a study by De Pauw et al. [27] carbon deposited on rough surfaces with high concentration of active sites was less ordered compared to PyC coatings on smooth surfaces. Concentration of active sites on the deposition substrate has been suggested to alter the composition of the gas phase[27] and also the surface reactions[28] and thus, affects the structure of deposited carbon. Similarly, during PyC deposition on AMWCNT sheets, the substrate 
for carbon deposition changes from pristine nanotubes, with smooth surfaces and low concentration of active sites, to deposited $\mathrm{PyC}$ with rougher surfaces and higher concentration of active sites. It has been shown that an optimum planar PyC structure results from a gas phase exhibiting an optimum ratio of polycyclic aromatic hydrocarbons (PAH) to small linear hydrocarbons[29-31]. When the concentration of active sites on the surface of the substrate is low (similar to the surface of pristine nanotubes), formation of $\mathrm{PAH}$ in the gas phase is favored. The optimum ratio between PAHs and linear hydrocarbons exists, leading to deposition of highly aligned PyC coating layers. In the opposite condition, deposition is controlled by heterogeneous reactions and a high concentration of active sites on the surface of the substrate prevents formation of PAHs. A disordered carbon structure is therefore formed likely due to the excess of small linear hydrocarbons in the deposited PyC layer. As it is shown in images 5.4A, 5.4C and 5.4E, this structure can be considered a non-graphitizable carbon as it did not rearrange during graphitization to form an ordered structure that resembles nanotube walls.

In contrast, for samples prepared by the cyclic graphitization method, graphitization was done after each deposition cycle. Since duration of a single deposition cycle (20 minutes) was shorter than the observed limit for formation of disordered carbon (30 minutes), the structure of carbon coating remained laminar and was fully graphitized during the first graphitization cycle. This graphitized coating layer was the substrate for the next PyC deposition cycle and since its surface characteristics were very similar to the surface of pristine nanotubes, development of disordered carbon during subsequent deposition cycles could be avoided. Therefore, graphene planes remained significantly 
aligned, even in thick PyC coatings. These coatings were successfully graphitized at the surface of nanotubes to significantly grow them in the radial direction. 

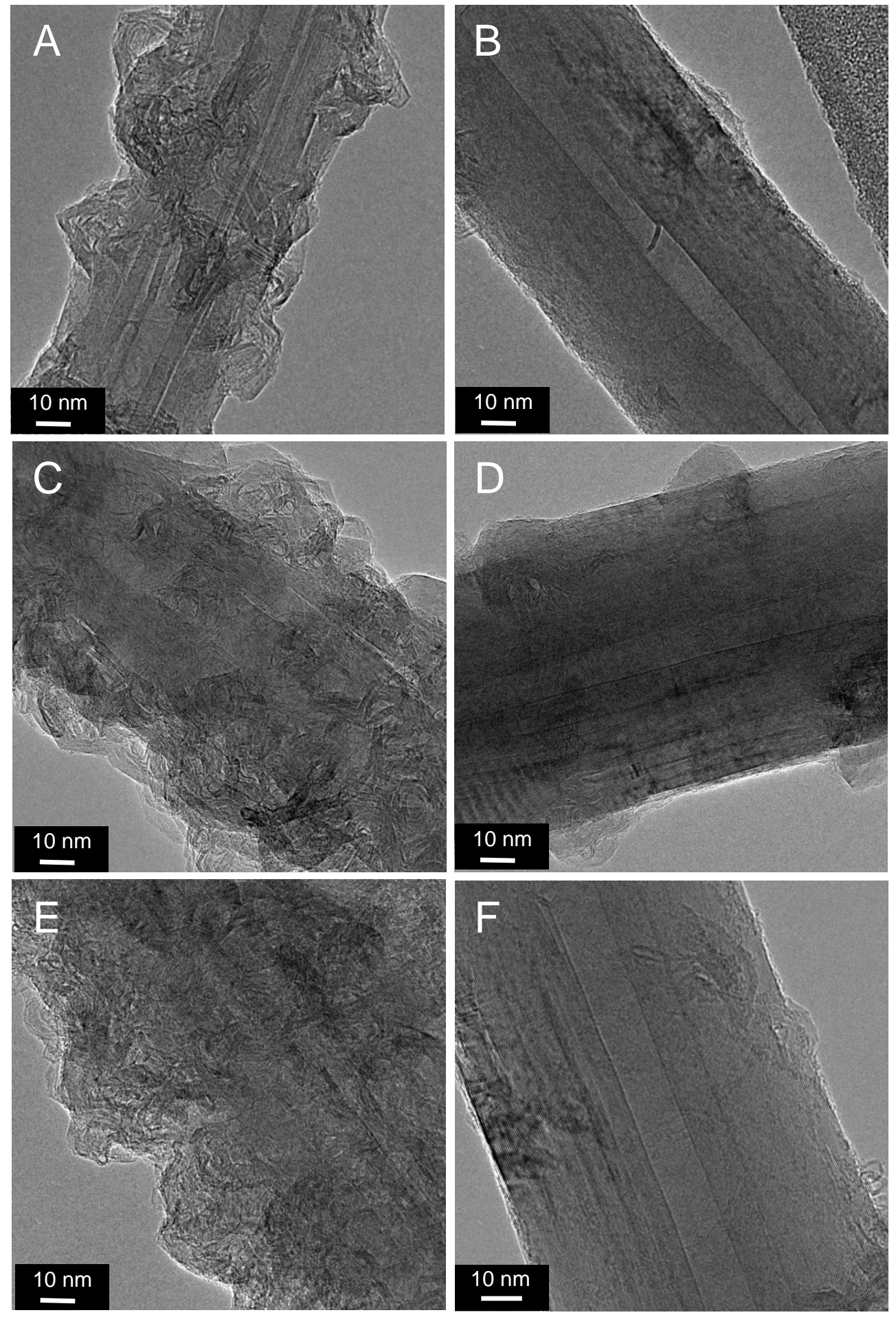

Figure 4 TEM images of samples with 2 (A\&B), 3 (C\&D) and 4 (E\&F) cycles of PyC coating prepared using one-step graphitization (left) and cyclic graphitization (right) method. 
TEM images were used to measure the thickness of coatings. Figure 5 shows changes in average diameter of CNTs with various PyC deposition cycles for samples prepared by both methods. Average diameter of the graphitized pristine nanotubes (Pristine G) was $40 \mathrm{~nm}$. After PyC coating, CNT diameter increased linearly and significantly. For cyclic graphitized samples, thickness of the coating layer increased from $\sim 18 \mathrm{~nm}$, after two cycles of deposition and graphitization, to $\sim 33 \mathrm{~nm}$ after 4 cycles. Using cyclic graphitization methods, we could tailor the structure of carbon coatings so that coatings with thicknesses up to $33 \mathrm{~nm}$ were successfully graphitized at the surface of nanotubes and radially grew CNTs. This is more than two times greater than the previously observed limit for the thickness of PyC coating which is able to be graphitized into additional tube walls on the surface of CNTs. Also, linear increase in CNTs diameter with deposition cycle helps to control the radial growth of nanotubes using cyclic graphitization method.

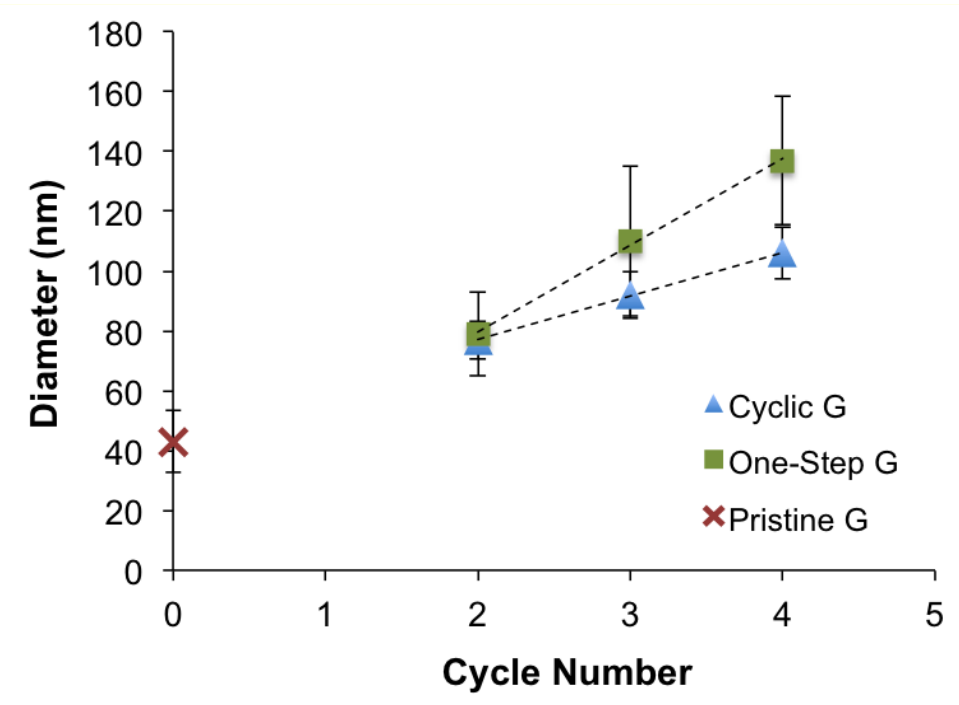

Figure 5 Variation in AMWCNT/C diameter with different PyC deposition cycles. 
It should be noted that large surface roughness of samples prepared using one-step graphitization route, resulted in large variation in the measured CNT diameters (standard deviation values between 13-24 nm). Cyclic graphitized samples had more uniform diameters as evidenced by smaller standard deviation values $(6-8 \mathrm{~nm})$.

Comparing graphs in Figure 3 and 5 shows that while the mass (and thus density) of AMWCNT/C composites increased with similar rates using both methods, the changes in tube diameters did not. In fact, the diameter of the nanotubes increased with a higher rate using one-step graphitization method. The much larger tube diameters of one-step graphitized samples were attributed to the increased level of structural disorder and corresponding decreased local density of the PyC coating layer.

\subsection{Structure of AMWCNT/C Composites}

Raman spectroscopy was used to further examine the structure of AMWCNT/C composites prepared using each method. In the Raman spectra of carbon materials, G-

band (centered around $1580 \mathrm{~cm}^{-1}$ ) corresponds to perfect graphitic structure and D-band (centered around $1350 \mathrm{~cm}^{-1}$ ) originates from defects[32]. Of particular interest is the integral intensity of D-band relative to that of $\mathrm{G}$-band $\left(\mathrm{R}=\mathrm{I}_{\mathrm{D}} / \mathrm{I}_{\mathrm{G}}\right)$, which is used to evaluate the defect density of carbon materials[33]. Consequently, $1 / \mathrm{R}$ is used to evaluate the crystal planar domain size. A higher $1 / \mathrm{R}$ value indicates a better graphitic structure. Each sample was scanned at 5 different locations and the average 1/R was calculated. As shown in Figure 6, despite doing prolonged graphitization runs on samples prepared by one-step graphitization method, the average $1 / \mathrm{R}$ values $(\leq 3.6)$ were lower than that of 
pristine AMWCNT sheets after graphitization $(\sim 5) .1 / \mathrm{R}$ also decreased when the number of PyC deposition cycles increased. Using the cyclic graphitization method, average 1/R value of samples with 2, 3 and 4 cycles of PyC deposition were all $\sim 5$ and very similar to that of graphitized pristine AMWCNT sheets.

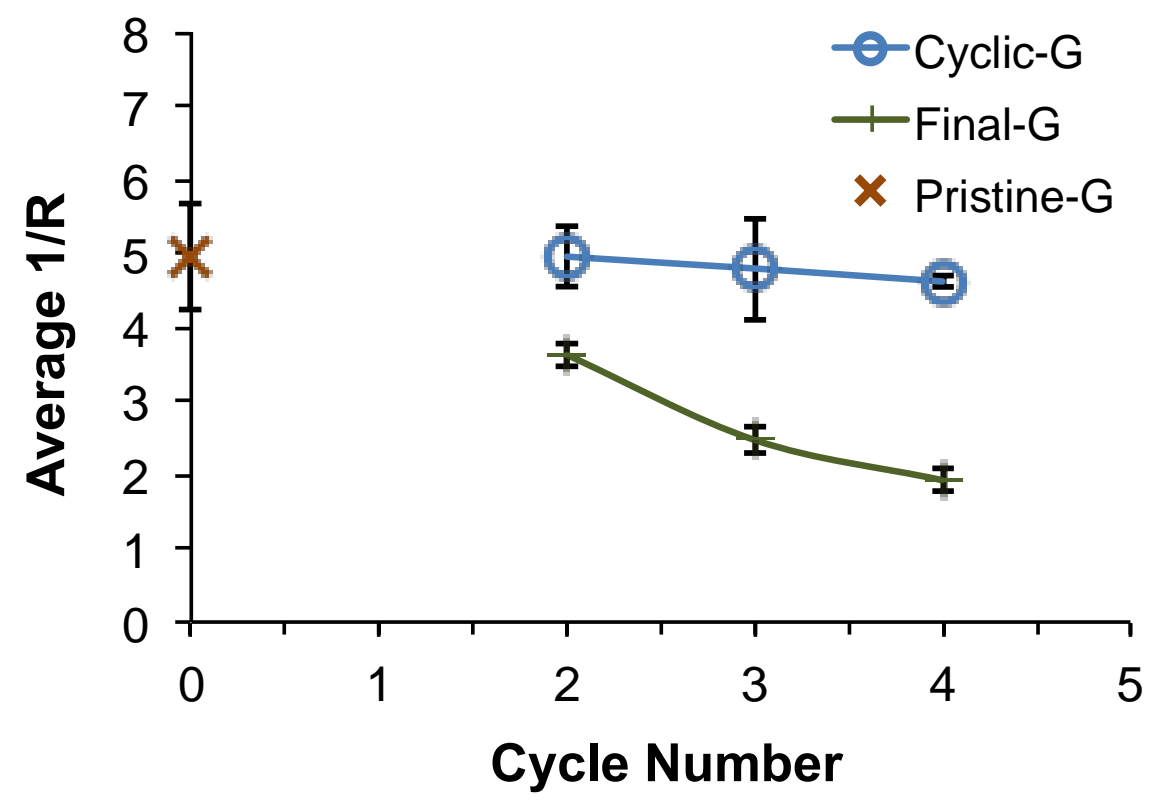

Figure 6 Average 1/R as a function PyC deposition cycle.

This result is in agreement with TEM observations indicating that graphitization after the formation of disordered carbon on CNT surface does not rearrange carbon layers into an highly ordered structure. However, if transition of coating structure into disordered carbon is avoided through cyclic graphitization, PyC coatings with large thickness can graphitize into additional walls on the surface of nanotubes.

Information about the average interlayer spacing $\left(\mathrm{d}_{002}\right)$ and graphitic stack size $\left(\mathrm{L}_{\mathrm{c}}\right)$ can be calculated using XRD spectra of samples. The characteristic peak at $\sim 26^{\circ}$ is attributed to $00 l$ lattice plane at 002 . Based on position and the full width half maximum 
(FWHM) of 002 peak, interlayer spacing and graphitic stack size were calculated using Bragg equation $\left(\mathrm{d}_{002}=\lambda / 2 \sin \theta_{002}\right)$ and Scherrer equation $\left(\mathrm{L}_{\mathrm{c}}=\mathrm{K} \lambda / \beta \cos \theta_{002}\right)$ [34], respectively. In these equations, $\mathrm{K}$ is a numerical factor frequently referred to as crystallite-shape factor $(\mathrm{K}=0.9)$ [34], $\lambda$ is the $\mathrm{x}$-ray wavelength, $\beta$ is FWHM of 002 peak, $\theta$ is position of 002 peak and. The degree of graphitization was also calculated using Maire and Mering equation[35,36]:

$$
g(\%)=\frac{0.3440-\mathrm{d} 002}{0.3440-0.3354} \times 100
$$

where $0.3440 \mathrm{~nm}$ and $0.3351 \mathrm{~nm}$ are d-spacings for fully non-graphitized carbon and ideal graphite crystal, respectively. It should be mentioned that while $0.3440 \mathrm{~nm}$ is considered as the limit for d-spacing of nongraphitic carbons by Franklin [37], sometimes the interlayer spacing of disordered carbon structures is greater than $0.3440 \mathrm{~nm}$, although this was not the case for samples measured in this work. The measured and calculated parameters for graphitized pristine nanotubes, $4 \mathrm{C} / \mathrm{G}$ and $4 \mathrm{C} / \mathrm{FG}$ composites are presented in Table 1.

Table 1 Measured and calculated structural parameters for different samples.

\begin{tabular}{ccccccc}
\hline Sample & $\begin{array}{c}2 \theta \\
(\text { degree })\end{array}$ & $\begin{array}{c}d_{002} \\
(\AA)\end{array}$ & $\begin{array}{c}\text { FWHM } \\
(\text { degree })\end{array}$ & $\begin{array}{c}\text { Lc } \\
(\mathrm{nm})\end{array}$ & $\mathrm{n}$ & G\% \\
\hline Pristine G & 26.14 & 3.4063 & 0.7263 & 12.18 & 35.76 & 39.22 \\
$4 \mathrm{C} / \mathrm{FG}$ & 26.05 & 3.4184 & 0.7452 & 11.86 & 34.71 & 25.17 \\
$4 \mathrm{C} / \mathrm{G}$ & 26.10 & 3.4119 & 0.5542 & 15.96 & 46.78 & 32.7 \\
\hline
\end{tabular}

In general, the AMWCNT/C composites have larger d-spacing compared to the graphitized pristine nanotubes. Also, the greater interlayer spacing in $4 \mathrm{C} / \mathrm{FG}$ sample 
compared to $4 \mathrm{C} / \mathrm{G}$ indicates that one-step graphitized samples are rougher and poorly graphitized as confirmed by TEM and Raman observations. Signification changes in the stack size of graphite were recorded. $\mathrm{L}_{\mathrm{c}}$ for graphitized pristine nanotubes was $12.18 \mathrm{~nm}$, and by dividing the stack height by the measured interlayer spacing for that sample, the average number of layers in the ordered graphitic regimes, n, was calculated to be 35 . Using the one-step graphitization method, $\mathrm{L}_{\mathrm{c}}$ and $\mathrm{n}$ decreased for the $4 \mathrm{C} / \mathrm{FG}$ composite due to the inability to fully graphitize the deposited carbon layers. A similar decrease in $\mathrm{L}_{\mathrm{c}}$ and $\mathrm{n}$ was reported in previous studies after carbon deposition on CNTs[11,21]. This decrease is due to the existence of the disordered structure at the surface of nanotubes, which leads to widening of the 002 peak. In samples prepared by the cyclic-graphitization method, however, $\mathrm{L}_{\mathrm{c}}$ increased due to graphitization of the deposited PyC layers and led to an increase in $\mathrm{n}$ from 35 to 46 . The calculated values for the degree of graphitization correlate well with structural observation from TEM and Raman studies. While AMWCNT/C composites prepared using either method had lower G (\%) compared to graphitized pristine CNTs, the degree of graphitization of cyclic-graphitized sample ( $\sim 33 \%)$ was higher than that of one-step graphitized composite ( $25 \%)$.

\subsection{Thermal Oxidation Stability of AMWCNT/C Composites}

Figure 7 shows TGA curves for Pristine G, 4 C/G and 4 C/FG samples. All three samples showed a minimal amount of mass loss between 200 and $400{ }^{\circ} \mathrm{C}$, indicating that they were nearly free of bulk amorphous carbon. The onset temperature for mass loss in graphitized pristine nanotubes was $748{ }^{\circ} \mathrm{C}$. For sample $4 \mathrm{C} / \mathrm{G}$, prepared with the cyclicgraphitization method, thermal oxidation was found to start at $743{ }^{\circ} \mathrm{C}$. These very close 
onset temperatures for thermal oxidation show that both samples have similar surface characteristics. However, onset temperature for thermal oxidation happened at a lower temperature $\left(663{ }^{\circ} \mathrm{C}\right)$ for samples prepared using the one-step graphitization route. This indicates that sample $4 \mathrm{C} / \mathrm{FG}$ has a greater concentration of defects, dangling bonds and incomplete layers on the surface, which are more reactive to oxygen compared to the basal graphene surfaces.

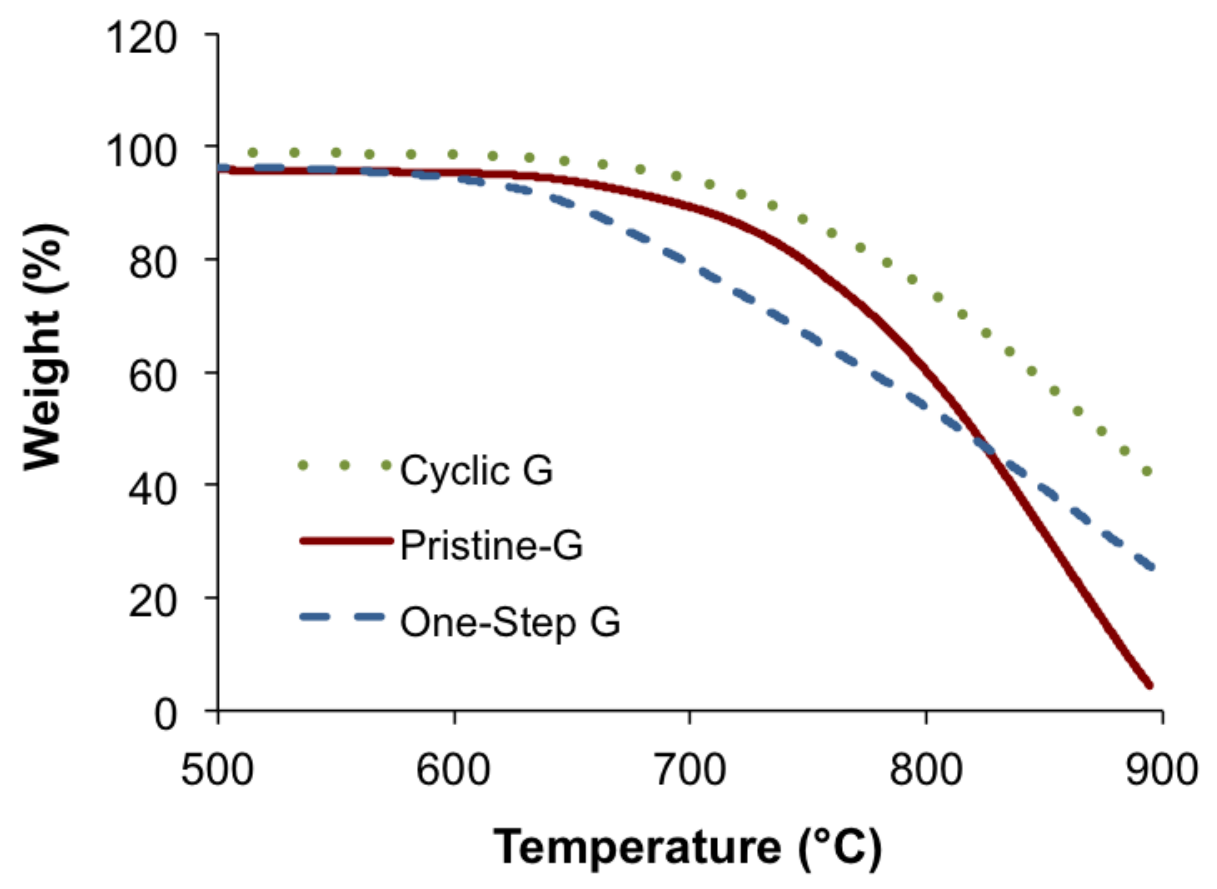

Figure 7 TGA curves of different samples.

\section{Conclusions}

Controlled radial growth of nanotubes was achieved using AMWCNT sheets and cyclic PyC depositions and graphitizations. TEM observations showed that the cyclic graphitization method avoided development of disordered carbon and led to significant 
alignment of graphene planes on the surface of nanotubes. In contrast, in the one-step graphitized samples, large amount of disorder carbon was developed during multiple cycles of PyC deposition. This disordered carbon structure was only partially graphitized during long graphitization run. Raman studies of cyclic graphitized samples showed that quality of radially grown nanotubes was very similar to pristine nanotubes after graphitization. Radial growth of CNTs was also confirmed in XRD findings, which showed that the average number of layers in ordered graphene regions (n) increased from 35, for graphitized pristine nanotubes, to 46 for sample with four cycles of PyC deposition prepared using cyclic graphitization method (4 C/G). TGA observations showed that cyclic graphitized samples had higher thermal oxidation stability based on their higher onset temperature for mass loss.

\section{Acknowledgment}

This work was supported by Air Force Office of Scientific Research grant no. FA955012-1-0088. The authors acknowledge the use of the Analytical Instrumentation Facility (AIF) at North Carolina State University, which is supported by the State of North Carolina and the National Science Foundation. The authors thank Prof. Jon-Paul Maria for use of the X-ray diffraction instrument.

\section{References}

[1] Gong Q, Li Z, Zhou X, Wu J, Wang Y, Liang J. Synthesis and characterization of in situ grown carbon nanofiber/nanotube reinforced carbon/carbon composites. Carbon 2005;43:2426-9. 
[2] Gong Q, Li Z, Zhang Z, Wu B, Zhou X, Huang Q et al. Tribological properties of carbon nanotube-doped carbon/carbon composites. Tribol Int 2006;39:937-44.

[3] Li X, Li K, Li H, Wei J, Wang C. Microstructures and mechanical properties of carbon/carbon composites reinforced with carbon nanofibers/nanotubes produced in situ. Carbon 2007;45:1662-8.

[4] Song Q, Li K, Li H, Li H, Ren C. Grafting straight carbon nanotubes radially onto carbon fibers and their effect on the mechanical properties of carbon/carbon composites. Carbon 2012.

[5] Xiao P, Lu X, Liu Y, He L. Effect of in situ grown carbon nanotubes on the structure and mechanical properties of unidirectional carbon/carbon composites. Materials Science and Engineering: A 2011;528:3056-61.

[6] Chen J, Xiong X, Xiao P. The effect of carbon nanotube growing on carbon fibers on the microstructure of the pyrolytic carbon and the thermal conductivity of carbon/carbon composites. Mater Chem Phys 2009;116:57-61.

[7] Lim D, An J, Lee HJ. Effect of carbon nanotube addition on the tribological behavior of carbon/carbon composites. Wear 2002;252:512-7.

[8] Li K, Li L, Li H, Song Q, Lu J, Fu Q. Electrophoretic deposition of carbon nanotubes onto carbon-fiber felt for production of carbon/carbon composites with improved mechanical and thermal properties. Vacuum 2014.

[9] Gong Q, Li Z, Li D, Bai X, Liang J. Fabrication and structure: a study of aligned carbon nanotube/carbon nanocomposites. Solid State Commun 2004;131:399-404.

[10] Li X, Ci L, Kar S, Soldano C, Kilpatrick SJ, Ajayan PM. Densified aligned carbon nanotube films via vapor phase infiltration of carbon. Carbon 2007;45:847-51.

[11] Yuguang J, Zhang Y, Zhang Q, Rufan Z, Li P, Qian W et al. Multiwall carbon nanotube-based carbon/carbon composites with three-dimensional network structures. Nanoscale 2013.

[12] Gong Q, Li Z, Bai X, Li D, Zhao Y, Liang J. Thermal properties of aligned carbon nanotube/carbon nanocomposites. Materials Science and Engineering: A 2004;384:20914.

[13] Ramos A, Cameán I, García AB. Graphitization thermal treatment of carbon nanofibers. Carbon 2013;59:2-32.

[14] Tzeng S, Lin Y. Formation of graphitic rods in carbon/carbon composites reinforced with carbon nanotubes. Carbon 2012. 
[15] Lanticse-Diaz LJ, Tanabe Y, Enami T, Nakamura K, Endo M, Yasuda E. The effect of nanotube alignment on stress graphitization of carbon/carbon nanotube composites. Carbon 2009;47:974-80.

[16] Prilutsky S, Zussman E, Cohen Y. The effect of embedded carbon nanotubes on the morphological evolution during the carbonization of poly (acrylonitrile) nanofibers. Nanotechnology 2008;19:165603.

[17] Allouche H, Monthioux M, Jacobsen RL. Chemical vapor deposition of pyrolytic carbon on carbon nanotubes: Part 1. Synthesis and morphology. Carbon 2003;41:2897912.

[18] Allouche H, Monthioux M. Chemical vapor deposition of pyrolytic carbon on carbon nanotubes. Part 2. Texture and structure. Carbon 2005;43:1265-78.

[19] Monthioux M, Allouche H, Jacobsen RL. Chemical vapour deposition of pyrolytic carbon on carbon nanotubes: Part 3: Growth mechanisms. Carbon 2006;44:3183-94.

[20] Zheng G, Sano H, Uchiyama Y. A layer-by-layer deposition mechanism for producing a pyrolytic carbon coating on carbon nanotubes. Carbon 2013.

[21] Faraji S, Stano K, Rost C, Maria J, Zhu Y, Bradford PD. Structural annealing of carbon coated aligned multi-walled carbon nanotube sheets. Carbon 2014.

[22] Yildiz O, Bradford PD. Aligned carbon nanotube sheet high efficiency particulate air filters. Carbon 2013;64:295-304.

[23] Chng ELK, Poh HL, Sofer Z, Pumera M. Purification of carbon nanotubes by high temperature chlorine gas treatment. Phys.Chem.Chem.Phys. 2013;15:5615-9.

[24] Bruneton E, Narcy B, Oberlin A. Carbon-carbon composites prepared by a rapid densification process II: structural and textural characterizations. Carbon 1997;35:1599611.

[25] Gerthsen D, Bach D, De Pauw V, Kalhoefer S, Reznik B, Send W. Structural properties of the fiber-matrix interface in carbon-fiber/carbon-matrix composites and interfaces between carbon layers and planar substrates. International journal of materials research 2006;97:1052-8.

[26] Bouchard E, Lavenac J, Roux J, Langlais F, Delhaès P. Pyrocarbon deposits on a graphite surface observed by STM. Chemical Vapor Deposition 2001;7:125-30.

[27] De Pauw V, Hawecker J, Schneider R, Send W, Wang X, Gerthsen D. Dependence of pyrocarbon microstructure on the substrate and annealing during the initial stage of chemical vapor deposition. Carbon 2008;46:236-44. 
[28] Norinaga K, Hüttinger KJ. Kinetics of surface reactions in carbon deposition from light hydrocarbons. Carbon 2003;41:1509-14.

[29] Hu Z, Zhang W, Hüttinger K, Reznik B, Gerthsen D. Influence of pressure, temperature and surface area/volume ratio on the texture of pyrolytic carbon deposited from methane. Carbon 2003;41:749-58.

[30] Zhang W, Hu Z, Hüttinger K. Chemical vapor infiltration of carbon fiber felt: optimization of densification and carbon microstructure. Carbon 2002;40:2529-45.

[31] Dong G, Hüttinger K. Consideration of reaction mechanisms leading to pyrolytic carbon of different textures. Carbon 2002;40:2515-28.

[32] Dresselhaus MS, Dresselhaus G, Saito R, Jorio A. Raman spectroscopy of carbon nanotubes. Physics Reports 2005;409:47-99.

[33] Cancado L, Takai K, Enoki T, Endo M, Kim Y, Mizusaki H et al. General equation for the determination of the crystallite size L a of nanographite by Raman spectroscopy. Appl Phys Lett 2006;88:163106,163106-3.

[34] Holzwarth U, Gibson N. The Scherrer equation versus the'Debye-Scherrer equation'. Nature Nanotechnology 2011;6:534-.

[35] Maire J, Mering J. Les Carbones. Masson et Cie 1965;1:129.

[36] Maire J, Mering J. Graphitization of soft carbons. Chemistry and physics of carbon 1970;6:125-90.

[37] Franklin RE. The structure of graphitic carbons. Acta Crystallogr 1951;4:253-61. 
${ }^{\star}$ Graphical Abstract

“Cyclic Graphitization” Method

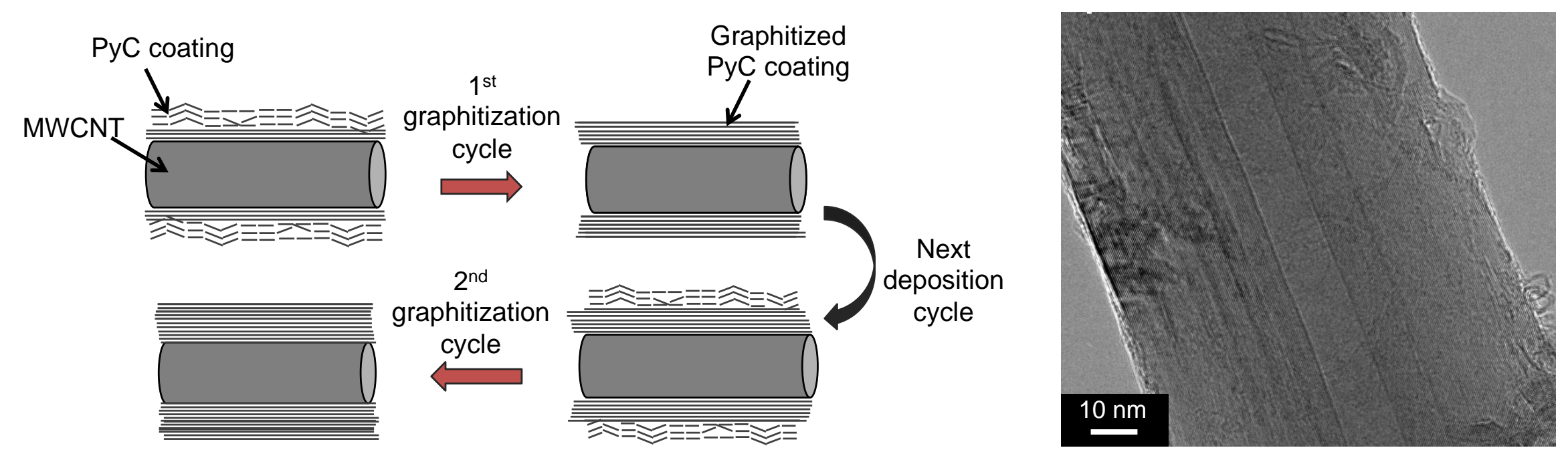

